\title{
Regional distribution of choline acetyltransferase in the human brain: changes in Huntington's chorea
}

\author{
S.-M. AQUILONIUS ${ }^{1}$, S.-Å. ECKERNÄS, AND A. SUNDWALL \\ From the Department of Neurology and Department of Pharmaceutical Pharmacology, \\ University of Uppsala, Sweden
}

SYNOPSIS A stereotaxic method of tissue sampling has been developed permitting detailed studies of the distribution of choline acetyltransferase (CAT) in brains from controls and from patients suffering from Huntington's chorea. The characteristic pattern of CAT distribution within extrapyramidal structures is described. In Huntington's chorea, CAT is unevenly reduced in several brain regions particularly in the rostromedial part of the caudate nucleus. The results indicate a preferential'degeneration of neostriatal cholinergic neurones in Huntington's chorea.

The primary biochemical defect in Huntington's chorea is unknown. There is indirect evidence to suggest that cholinergic hypofunction in neostriatal mechanisms might play a pathophysiological role in hyperkinesia. Anticholinergic agents aggravate chorea, while reduced hyperkinesia has been reported after physostigmine (Aquilonius and Sjöström, 1971; Klawans and Rubowits, 1972). The low concentrations of cerebrospinal fluid choline $(\mathrm{Ch})$ often found in patients with Huntington's chorea (Aquilonius et al., 1972) also emphasize the need for extended studies on central cholinergic mechanisms in this disease.

Choline acetyltransferase (CAT), the enzyme catalysing the formation of acetylcholine (ACh), is regarded as a specific marker of cholinergic representation in brain tissue (review by Fonnum, 1973). The bulk of enzyme is localized in the nerve terminals of the cholinergic neurone. Accordingly, a loss of CAT activity reflects degeneration of cholinergic terminals.

In the present investigation, a stereotaxic method was used which enabled a detailed mapping of the distribution of CAT in the human brain. A characteristic pattern of CAT reduction in Huntington's chorea is discussed in

1 Address for correspondence: S.-M. Aquilonius, Department of Neurology, University Hospital, Fack, S-750 14 Uppsala 14, Sweden. (Accepted 24 February 1975.) relation to present pathological and neuropharmacological knowledge.

\section{METHODS}

NECROPSY MATERIAL Controls 1. B 20 Female. Age: 53 years. No history of neurological disease. Progressive heart failure of unknown aetiology for several years. Drugs: digitalis, various diuretics, and antiarrhythmic drugs. Clinical note: ventricular arrhythmia. Necropsy: unspecific cardiomyopathy. Brain frozen seven hours post mortem.

2. A 88 Female. Age: 85 years. No history of neurological disease. Three months' history of dyspnoea and angina pectoris. Drugs: digitalis and diuretics. Clinical note: sudden heart failure. Necropsy: pulmonary emboli and myocardial infarction. Brain frozen six hours post mortem.

Patients with Huntington's Chorea 1.V32 Female. Age: 43 years. Symptoms: progressive dementia and chorea over nine years. Diagnosis confirmed in Swedish population study (Mattsson, 1974). Not bedridden but severe dementia and pronounced chorea. Drugs: neuroleptic agents and for the last year lithium. Clinical note: unexpected sudden death. Necropsy: pulmonary oedema. Right hemisphere frozen 21 hours post mortem.

2. M 21 Male. Age: 52 years. Symptoms: psychiatric symptoms, alcohol abuse, epileptic seizures of 17 years' duration. Choreatic movements of seven 
years' duration. Diagnosis confirmed in Swedish population study (Mattsson, 1974). Advanced dementia, bedridden last two years. Drugs: neuroleptic agents, carbamazepine and, during the last year, lithium. Clinical note: successive general deterioration, fever. Necropsy: cardiosclerosis, pulmonary oedema, and bronchopneumonia. Left hemisphere frozen 31 hours post mortem.

TISSUE SAMPLING The brain was carefully divided in the midsagittal line. The hemisphere was slowly frozen with the sagittal plane facing down on a glass plate. When frozen, steel pins were introduced through the anterior $(\mathrm{cm} . \mathrm{a})$ and the posterior (cm.p) commissure at right angles to the sagittal plane. A block extending from $10 \mathrm{~mm}$ in front of $\mathrm{cm}$. a to $5 \mathrm{~mm}$ behind $\mathrm{cm}$.p was cut out and embedded in carboxymethylcellulose. The block was mounted in a heavy cryomicrotome (PMW 400, Palmstiernas

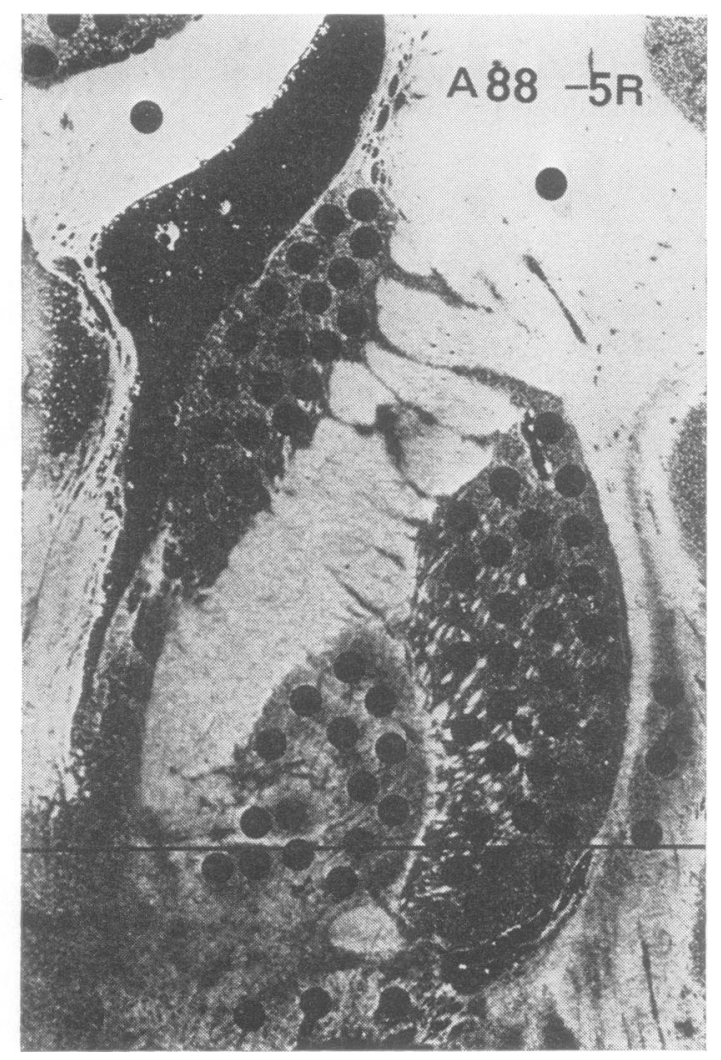

FIG. 1 The distribution of punchings in a typical section from a right hemisphere of $A 88,5 \mathrm{~mm}$ behind the anterior commisure.
Mek. Verkstad, Stockholm, Sweden) so that a frontal section plane was obtained perpendicular to the intercommissural and the sagittal planes. In these pertinent sections $(+5 \mathrm{~mm},-5 \mathrm{~mm},-10 \mathrm{~mm}$, $-20 \mathrm{~mm}$ in relation to $\mathrm{cm}$.a) transparent tape (Scotch tape no. 810) was applied to the block surface. The $200 \mu \mathrm{m}$ cut sections were thus obtained on tape strips. The ideal temperature for sectioning was around $-18^{\circ} \mathrm{C}$. Immediately after sectioning tissue samples were punched out on a cooled $\left(-5^{\circ} \mathrm{C}\right)$ metal plate. Standardized glass capillaries (Microcaps $50 \mu \mathrm{l})$ were siliconized and used as punch-tools. This punching procedure gives a reproducible volume of tissue which makes it possible to relate CAT activity per $\mathrm{mm}^{3}$ of tissue. (Total error of CAT assay as calculated from punchings of white matter less than $\pm 5 \%, n=15$.) About 100 specimens were taken out from each section. Samples were blown out into microtubes and stored in a freezer $\left(-25^{\circ} \mathrm{C}\right)$ until analysed. All sections were photographed before and after punching (Fig. 1).

CAT DETERMINATION The procedure used differs in some details from an earlier published modification (Glover and Green, 1972) of the radiochemical method described by Fonnum (1969). To each microtube $10 \mu \mathrm{l}$ homogenization mixture $(1 \%$ butanol; $150 \mathrm{mM}-\mathrm{NaCl} ; 0.2 \mathrm{mM}-$ EDTA) were added together with a small glass rod to facilitate homogenization on a vortex mixer. The tissue to solvent ratio was $1: 100(\mathrm{w} / \mathrm{v})$. After adding $10 \mu \mathrm{l}$ $\left(140 \mu \mathrm{M}-\left[{ }^{14} \mathrm{C}\right]\right.$ acetyl-CoA $(50 \mathrm{mCi} / \mathrm{mmol}$, New England Nuclear); $10 \mathrm{mM}$-choline chloride; 200 $\mathrm{mM}-\mathrm{KCl} ; 20 \mathrm{mM}$ phosphate buffer, $\mathrm{pH} \mathrm{7.0;}$ and $0.2 \mathrm{mM}$ - physostigmine salicylate) incubation was performed at $37^{\circ} \mathrm{C}$ for 10 minutes (high activity regions; caudate nucleus and putamen), or 60 minutes (other regions). Under these conditions, the reaction followed first order kinetics. It was controlled so that the enzyme was stable during the incubation period. The reaction was stopped by adding $10 \mu \mathrm{l} 1 \mathrm{M}$-HAc. In order to extract ACh formed, $100 \mu$ l extraction mixture (0.1 $\left.\mathrm{M} \mathrm{K}_{2} \mathrm{Hg} \mathrm{I}_{4}\right)$ dissolved in heptanone-(3) was added to each tube, which was shaken for $3 \times 1.0 \mathrm{~min}$ on the mixer and then centrifuged for $1.0 \mathrm{~min}$ to separate the layers; $50 \mu \mathrm{l}$ of the organic upper layer was withdrawn and added to $10 \mathrm{ml}$ scintillation cocktail $(7 \mathrm{ml}$ toluene; $3 \mathrm{ml}$ methanol, and $55 \mathrm{mg}$ Permablend-III, Packard). A Nuclear Chicago Scintillation counter (Isocap 300) was used. Less than $0.5 \%$ radioactive acetyl-CoA was extracted to the organic layer and gave rise to blank values of about $900 \mathrm{dpm}$. The $\left[{ }^{14} \mathrm{C}\right]-\mathrm{ACh}$ formed was extracted with $98 \%$ efficiency. It was determined by high voltage paper electrophoresis ( $\mathrm{pH} 4.6$; pyridine, acetic acid acetone and water; $8: 8: 30: 154$ by vol.) that 


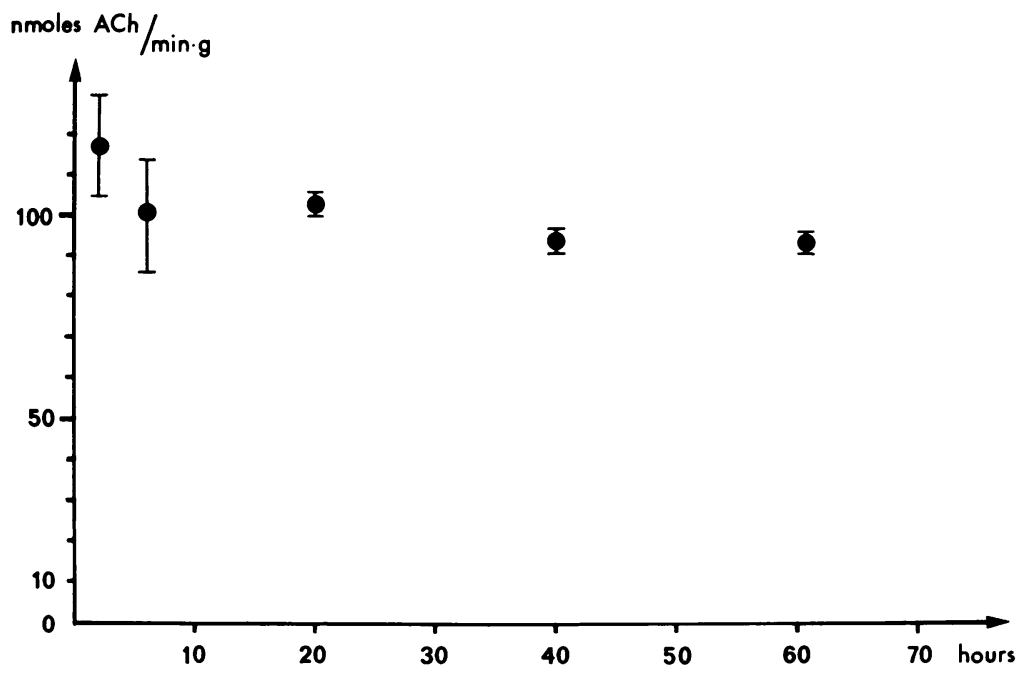

FIG. 2 Choline acetyltransferase $(C A T)$ activity versus different post mortem times. Each point represents two to six caudatal samples from one brain.
ACh was the only radioactive metabolite formed upon incubation of human brain tissue.

Enzyme stability Several authors have documentated stable CAT-activities in intact brain tissue for two to three days post mortem (Hebb and Silver, 1956; Wise et al., 1974) and in a frozen $\left(-25^{\circ} \mathrm{C}\right)$ homogenate for 90 days (Johnson and Domino, 1971). To control the CAT stability under necropsy conditions in the present study, samples from the rostral part of caudate nuclei were removed at routine necropsies performed at different post mortem time intervals. No significant changes were found in the time interval two to 62 hours post mortem (Fig. 2). The somewhat lower absolute values as compared with our microassays in frozen sections are explained by a less complete enzyme activation in the large homogenates.

EVALUATION PROCEDURE From the photograph (Fig. 1) every section was reproduced on transparent paper and all CAT values were put in. Left side sections were reversed and all control brain sections from corresponding sites were calculated together. Values were grouped until significant differences $(P<0.001$, Student's $t$ test $)$ between neighbouring populations (Table 1, Figs 3 and 4) were obtained. In the individual sections from the chorea brains every value is compared with the corresponding population in the control material.

\section{RESULTS}

CONTROLS The distribution of CAT activities in the analysed structures is illustrated in Fig. 3
TABLE 1

CAT ACTIVITY IN DIFFERENT REGIONS OF HUMAN BRAIN

\begin{tabular}{|c|c|c|c|}
\hline \multirow[t]{2}{*}{ Structure } & \multirow{2}{*}{$\begin{array}{l}\text { Popula- } \\
\text { tion } \\
\text { area }\end{array}$} & \multicolumn{2}{|c|}{$\begin{array}{c}\text { CAT activity } \\
\left(\text { nmole } A C h / \min \cdot \mathrm{cm}^{3}\right)\end{array}$} \\
\hline & & $\pm S E(n)$ & No. \\
\hline Caudate nucleus & $\begin{array}{l}\text { Cd1 } \\
\text { Cd2 } \\
\text { Cd3 } \\
\text { Cd4 }\end{array}$ & $\begin{array}{r}108.7 \pm 8.3 \\
194.1 \pm 4.0 \\
151.3 \pm 6.5 \\
91.8 \pm 4.7\end{array}$ & $\begin{array}{l}13 \\
98 \\
43 \\
27\end{array}$ \\
\hline Putamen & $\begin{array}{l}\text { Pt1 } \\
\text { Pt2 } \\
\text { Pt3 }\end{array}$ & $\begin{array}{l}237.5 \pm 3.9 \\
319.3 \pm 7.6 \\
180.4 \pm 16.5\end{array}$ & $\begin{array}{r}147 \\
34 \\
9\end{array}$ \\
\hline Globus pallidus lateralis & $\begin{array}{ll}\text { Pl } & 1 \\
\text { Pl } & 2 \\
\text { Pl } & 3\end{array}$ & $\begin{array}{r}12.4 \pm 1.0 \\
8.7 \pm 0.3 \\
15.1 \pm 1.8\end{array}$ & $\begin{array}{l}15 \\
41 \\
31\end{array}$ \\
\hline Globus pallidus medialis & P.m & $4.5 \pm 0.2$ & 31 \\
\hline Nucleus ansa lentiformis & A.1 & $35.4 \pm 7.1$ & 14 \\
\hline $\begin{array}{l}\text { Claustrum }+5 \\
\text { Claustrum }-5,-10,-20\end{array}$ & $\begin{array}{l}\mathrm{Cl} \\
\mathrm{Cl}\end{array}$ & $\begin{array}{r}4.9 \pm 0.4 \\
10.4 \pm 0.5\end{array}$ & $\begin{array}{r}9 \\
35\end{array}$ \\
\hline $\begin{array}{l}\text { Substantia nigra pars compacta } \\
\text { Substantia nigra pars reticulata }\end{array}$ & $\begin{array}{l}\text { Ni.c } \\
\text { Ni.r }\end{array}$ & $\begin{array}{l}5.9 \pm 0.5 \\
3.2 \pm 0.1\end{array}$ & $\begin{array}{l}11 \\
15\end{array}$ \\
\hline Subthalamic nucleus & Sth & $12.2 \pm 0.9$ & 15 \\
\hline Nucleus ruber & $\mathbf{R u}$ & $5.0 \pm 0.1$ & 2 \\
\hline $\begin{array}{l}\text { Thalamus medial part } \\
\text { Thalamus lateral part } \\
\text { Substantia reticularis thalami }\end{array}$ & $\begin{array}{l}\text { Th.m } \\
\text { Th.1 } \\
\text { Rt }\end{array}$ & $\begin{array}{r}10.5 \pm 0.6 \\
6.4 \pm 0.3 \\
4.9 \pm 0.3\end{array}$ & $\begin{array}{l}33 \\
73 \\
15\end{array}$ \\
\hline Amygdala & Am & $25.6 \pm 2.7$ & 61 \\
\hline $\begin{array}{l}\text { Gyrus cinguli } \\
\text { Gyrus olfactorius } \\
\text { Insula } \\
\text { Hippocampus }\end{array}$ & $\begin{array}{l}\text { G.c } \\
\text { G.ol } \\
\text { Cx.in } \\
\text { Hipp }\end{array}$ & $\begin{array}{r}4.5 \pm 0.1 \\
10.0 \pm 0.8 \\
8.6 \pm 0.6 \\
13.6 \pm 1.5\end{array}$ & $\begin{array}{r}5 \\
13 \\
6 \\
17\end{array}$ \\
\hline White substance & $\mathbf{w}$ & $1.9 \pm 0.1$ & 14 \\
\hline
\end{tabular}



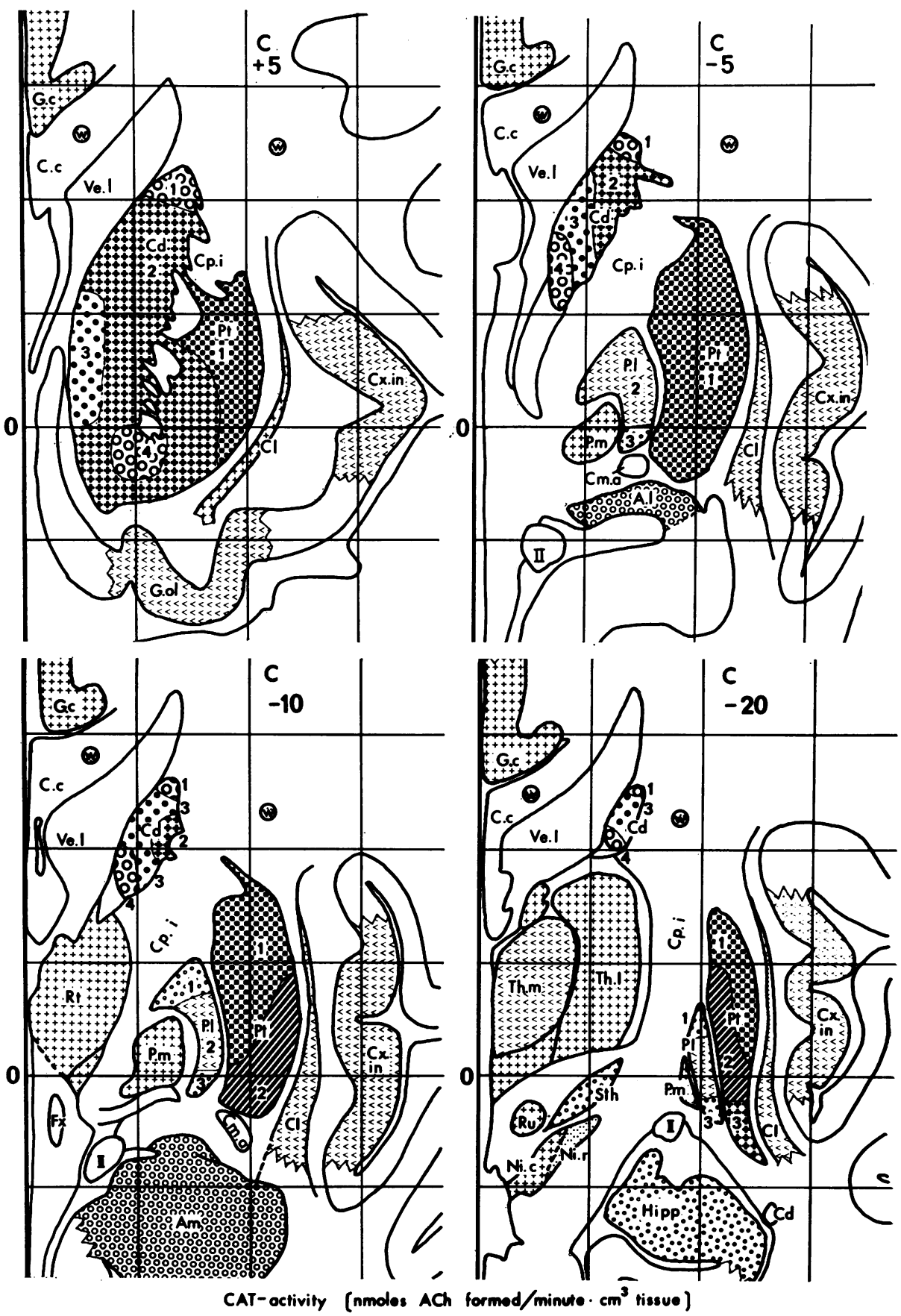

ACh formod/minute. $\mathrm{cm}^{3}$ tissue]
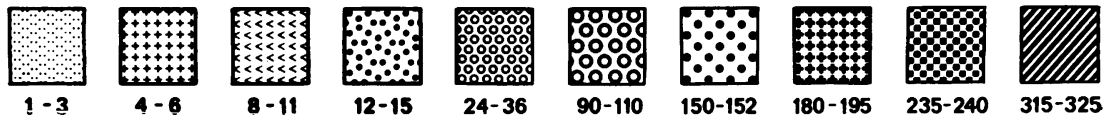

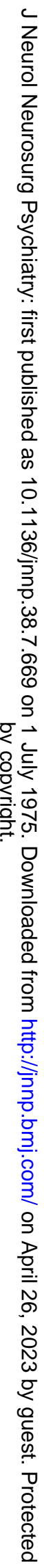


and numerically presented in Table 1 . As the primary aim of the present investigation was to map cholinergic representation within the striatal system, the number of analyses was very high in these structures. CAT activity regions demarcated in the different sections represent parts of sterically distributed populations. The caudate nucleus and the putamen show the highest CAT activities with about 10-15 times higher enzyme values than the other regions analysed. In the caudate nucleus four parts were identified (Cdl-Cd4). The highest activity in the caudate nucleus, $\mathrm{Cd} 2$, occupies a large area in the rostral part of the nucleus, where it extends into the ventrorostral part of the putamen. $\mathrm{Cd} 2$ is subsequently diminished posteriorly. In the putamen, which as a whole shows higher CAT-values than the caudate nucleus, a very high activity population, $\mathrm{Pt} 2$ is found in the two posterior sections $(-10,-20 \mathrm{~cm} . \mathrm{a})$.

In all the other regions that were analysed a much lower CAT activity was demonstrated. However, in the amygdala where no significantly different subpopulations could be depicted the CAT range (10-140 nmole $\left.\mathrm{ACh} / \mathrm{min} \cdot \mathrm{mm}^{3}\right)$ indicated that small parts with high cholinergic density are present.

The lateral pallidum was found to have about double the CAT values of the medial. The former could be further subdivided into three parts (P1 2-3) with higher activities in the ventral and the dorsal portion of the nucleus.

Very low activity is localized to the pars reticulata of the substantia nigra $(\mathrm{Ni} \cdot \mathrm{r})$, while in the pars compacta $(\mathrm{Ni} \cdot \mathrm{c})$ significantly higher values were found.

Apart from a medial and a lateral region in the thalamus, no further subareas could be statistically determined in the present investigation.

In the other regions presented in Table 1, the CAT values represent the means of relatively few scattered punchings.
HUNTINGTON'S CHOREA The results are shown in Figs 4 and 5. In both brains from patients with Huntington's chorea extreme reductions in CAT activities were found in the neostriata. In the most rostral section $(+5 \mathrm{~mm})$, only $4 \%$ (M 21) and $11 \%$ (V 32) of normal CAT activity remained in the paraventricular part of the caudate nucleus. No reproducible system was traced regarding the patchy distribution of CAT reductions in other parts of the neostriatum. In M 21 reductions within the putamen were pronounced, especially in the posterior sections $(-10,-20 \mathrm{~mm})$ where normal activities were found in V 32 (Figs 4 and 5).

In most other regions, CAT activities were normal or slightly reduced. In both cases elevated activities were found in the gyrus cinguli and in V 32 in some parts of the thalamus, the claustrum, and the pallidum.

\section{DISCUSSION}

It has been concluded from animal experiments (review by Fonnum, 1973) that CAT is a reliable marker of cholinergic representation, while the distribution of acetylcholinesterase (AChE) 'can indicate the sites at which cholinergic mechanisms may operate and reinforce evidence for the existence of cholinergic mechanisms derived from other approaches' (cited from Silver, 1967). In addition, when the present results are compared with earlier investigations on the histochemistry of AChE in human brains, some discrepancies are obvious. In sections histochemically stained for AChE (review by Ishii and Friede, 1967), the pallidum seems to have nearly as high a cholinergic density as the caudate nucleus and the putamen. In human biochemical studies also, the differences in AChE activity between the pallidum and the neostriatum are rather small (Rinne et al., 1973). However, in the present investigation it was

FIG. 3 Normal distribution of choline acetyltransferase (CAT) in different regions of human brain (5 mm rostral and 5, 10, and $20 \mathrm{~mm}$ behind the anterior commisure). Abbreviations: A.1-nucleus ansa lenticularis, Amamygdala, $\mathrm{Cd}$-caudate nucleus, C.c-corpus callosum, $\mathrm{Cl}$-claustrum, Cm.a-anterior commissure, Cp.iinternal capsule, Cx.in-insula, Fx-fornix, G.c-gyrus cinguli, G.ol-gyrus olfactorius, Hipp-hippocampus, Ni.c_substantia nigra pars compacta, Ni.r-substantia nigra pars reticulata, Pl—lateral pallidum, $\mathrm{Pm}-$ medial pallidum, $\mathrm{Pt}$-putamen, $\mathrm{Rt}$-substantia reticularis thalami, $\mathrm{Ru}$-nucleus ruber, $\mathrm{Sth}-$ subthalamic nucleus, Th.l-thalamus lateral part, Th.m-thalamus medial part, $\mathrm{w}-$ white substance. White areas =not analysed. 

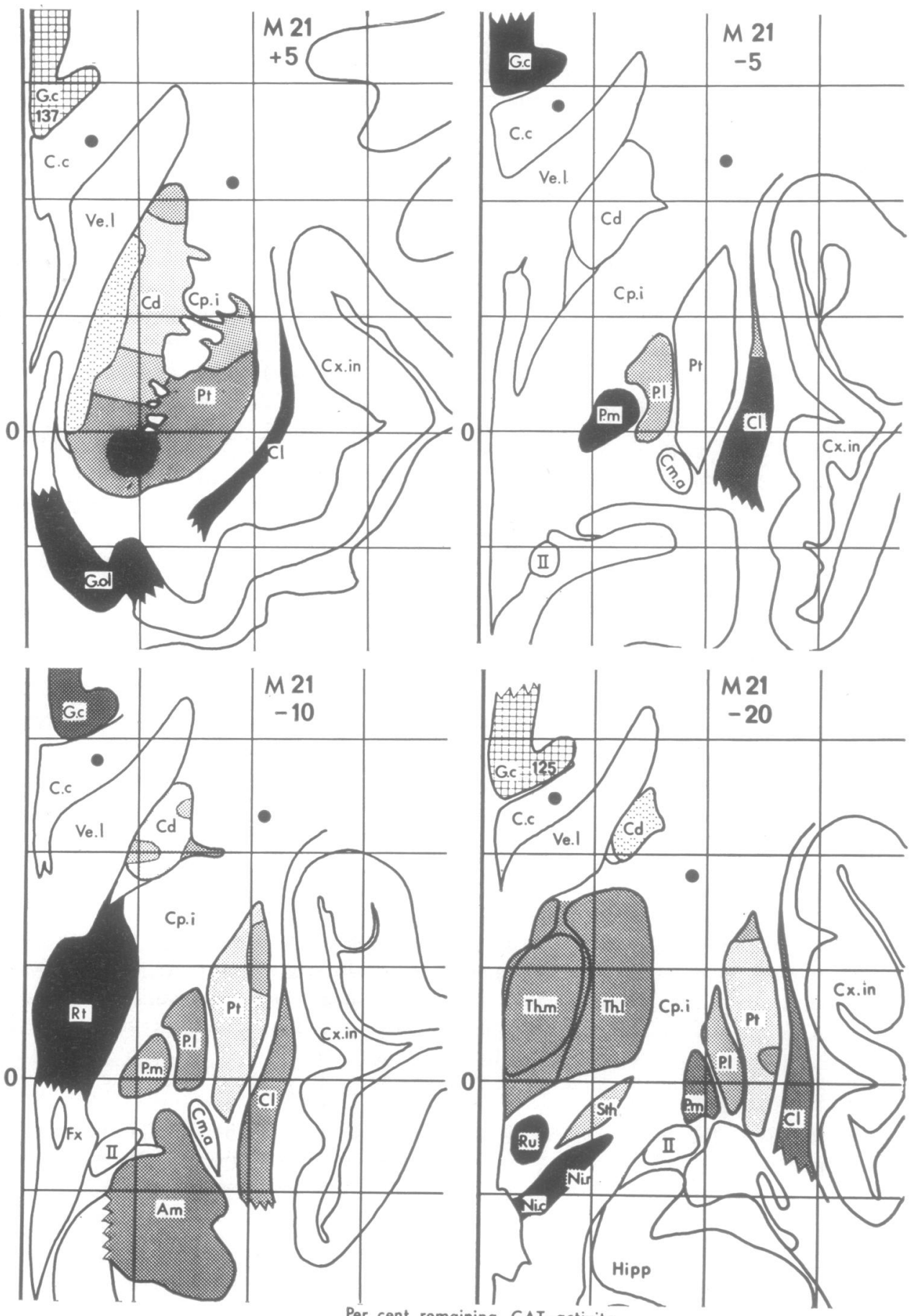

Per cent remaining CAT-activity
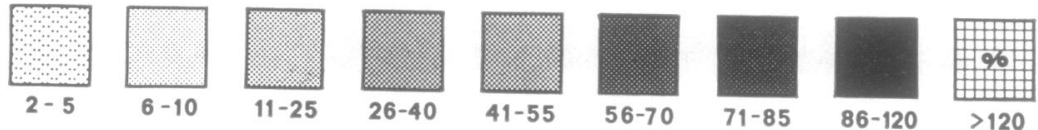

FIG. 4 Brain choline acetyltransferase (per cent of control values) in one patient with Huntington's chorea, M 21. Abbreviations as in Fig. 3. White areas: not analysed. 

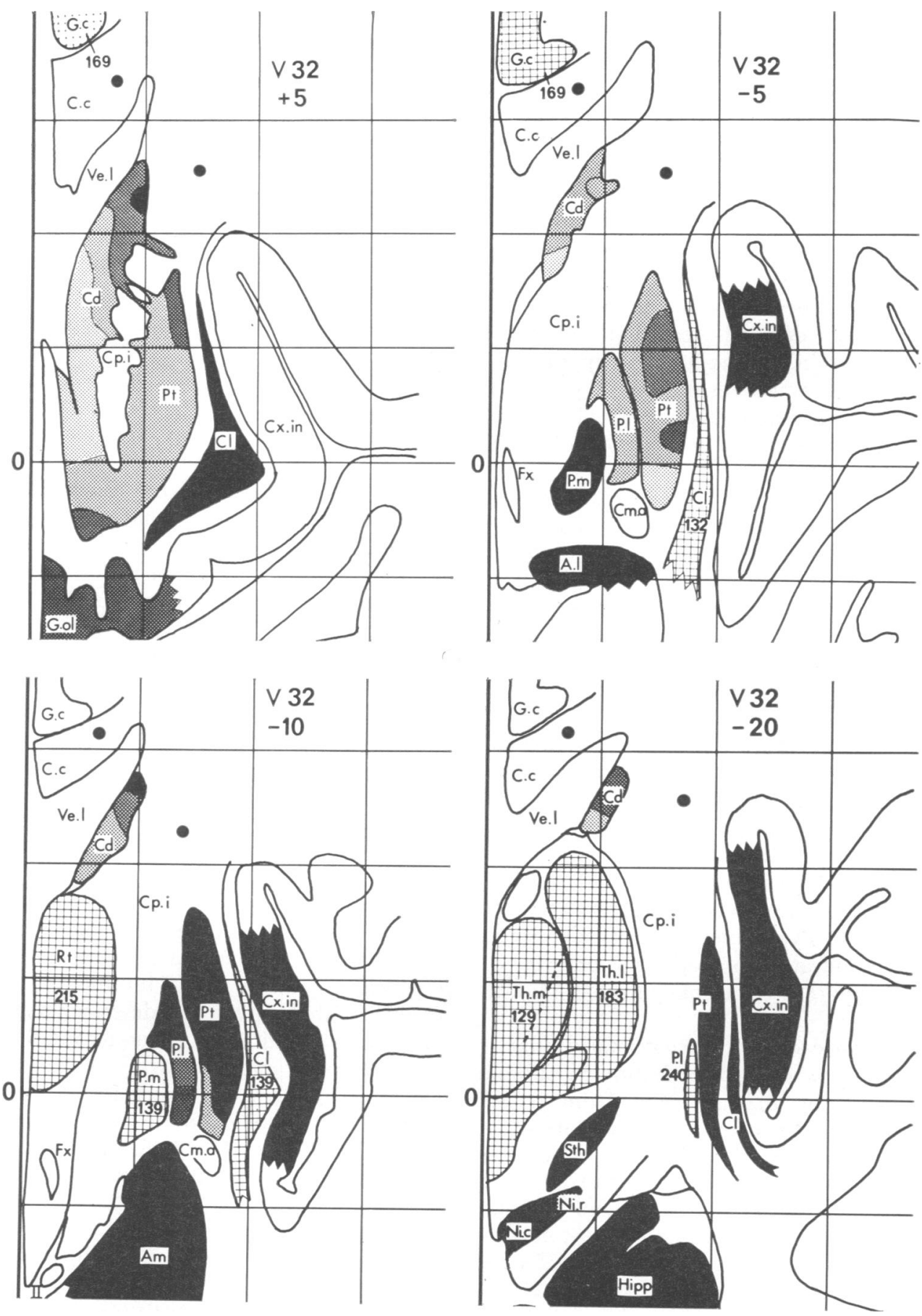

FIG. 5 Brain choline acetyltransferase (per cent of control values) in one Huntington's chorea patient, V 32. Abbreviations as in Fig. 3. Key as in Fig. 4. 
demonstrated that the cholinergic representation within the neostriatum is at least 10 times higher than in the pallidum. The substantia nigra has also a relatively higher activity of AChE (McGeer and McGeer, 1971) than of CAT. The differences can be explained by different distribution of CAT and AChE within cholinergic neurones and association of AChE with noncholinergic elements in the CNS (Emson and Fonnum, 1973; Hemminki et al., 1973).

With the present stereotaxic method of tissue sampling, it has been possible to perform the presently most detailed mapping of CAT distribution within the human extrapyramidal system. A higher level of resolution will probably have to await an immunohistochemical method based on advances in the purification of CAT (Rossier et al., 1973).

Enzyme activities are often calculated in relation to wet weight, dry weight, total protein, or intracellular markers such as potassium or lactate dehydrogenase. There are no theoretical advantages of these procedures in comparison with the one $\left(\mathrm{CAT} / \mathrm{mm}^{3}\right)$ used in the present investigation. The punching from tape strips is a rapid method of obtaining reproducible tissue volumes.

Several anatomical regions can be subdivided according to differences in CAT activity. Especially in the caudate nucleus different populations can be traced sterically through the sections (Fig. 3). Little is as yet known about eventual physiological correlates to these subnuclear regions. However, it is interesting to note that choreiform hyperkinesia in cats is induced after local application of dopamine only in the rostromedial part of the caudate nucleus (Cools, 1972).

Disappearance of small neostriatal (Golgi II type) neurones is a classical feature in choreic brains (review by Bruyn, 1968; Dom et al., 1973). According to Bruyn, these cells are often preserved in the accumbens nucleus (where the caudate nucleus and putamen fuse rostrally, +5 section), a region where we found normal enzyme activity in case $M 21$ and almost normal values in case $\mathrm{V}$ 32. The reductions in CAT were found to be patchy in both cases of Huntington's chorea. This was recently indicated in a study by McGeer et al. (1973). However, extreme reductions are localized in the rostromedial part of the
TABLE 2

PERCENT REDUCTION OF NEOSTRIATAL CATECHOLAMINERGIC MARKERS IN HUNTINGTON'S CHOREA

\begin{tabular}{lccccc}
\hline & & $D A$ & $H V A$ & $N A$ & $T H$ \\
\hline Bernheimer and & NC & 41 & 32 & NS & \\
$\quad$ Hornykiewicz (1973) & P & NS & NS & NS & \\
Bird and Iversen & NC & NS & & & NS \\
$\quad$ (1974) & P & NS & & & NS \\
Mattsson (1974) & NC & NS & 47 & NS & \\
& P & NS & NS & NS & \\
McGeer et al. (1973) & NC & & & & NS \\
& P & & & & NS
\end{tabular}

Abbreviations: dopamine (DA); homovanillic acid (HVA); noradrenaline (NA); tyrosine hydroxylase (TH); caudate nucleus (NC); putamen (P); non-significant (NS).

caudate nucleus (Figs 4 and 5). Bird and Iversen (1974) recently reported that $\gamma$-aminobutyric acid and glutamic acid decarboxylase are also reduced in chorea brains. The pathophysiological rôle of this interesting finding is hard to interpreto at present.

Animal experiments strongly suggest that a major part of the neostriatal cholinergic repre sentation is attributed to interneurones (McGeer et al., 1971; Lynch et al., 1972). One may therefore conclude that the reduction of CAT rather specifically localized to the neostriatum in chorea brains is the biochemical evidence of a loss of small cholinergic interneurones. The reductions were less pronounced in $\mathrm{V} \mathrm{32}$, who unexpectedly died in a less advanced stage of the disease. A preferential degeneration of cholinergic neostriatal interneurones in the hyperkinetic hypotonic syndrome of Huntington's chorea would fit with the previously described pharmacological manipulations (Aquilonius and Sjöström, 1971; Klawans and Rubovits, 1972). Catecholaminergic markers are reported to be preserved or moderately reduced in the striata of Huntington's chorea brains (Table 2). In the late rigid stages and in the Westphal variant also nigroneostriatal dopaminergic projections might be severely affected, as indicated in studies on the concentration of homovanillic acid in the CSF (Curzon et al., 1972).

In conclusion, several anatomical structures in the human brain can be subdivided according to differences in cholinergic representation. More- 
over, the present investigation supports a theory of a primary degeneration of cholinergic neostriatal interneurones in Huntington's chorea. Similar studies in cortical degenerations, the morphological correspondents of dementia, are lacking.

This work was supported by the Swedish Medical Research Council (Grants no. B-75-04X-4373-02) and by grants from the Harald and Greta Jeansson foundation and from the Tore Nilson foundation for medical research. The authors are indebted for skilful assistance to Miss Inger Falk and Miss Lena Persson. We should like to thank Professor S. Ullberg for advice concerning the cryomicrotome.

\section{REFERENCES}

Aquilonius, S.-M., and Sjöström, R. (1971). Cholinergic and dopaminergic mechanisms in Huntington's chorea. Life Sciences, pt 1, 10, 405-414.

Aquilonius, S.-M., Nyström, B., Schuberth, J., and Sundwall, A. (1972). Cerebrospinal fluid choline in extrapyramidal disorders. Journal of Neurology, Neurosurgery, and Psychiatry, 35, 720-725.

Bernheimer, H., and Hornykiewicz, O. (1973). Brain amines in Huntington's chorea. In Advances in Neurology, 1, 525531. Edited by A. Barbeau, T. N. Chase, and G. W. Paulson. Raven Press: New York.

Bird, E. D., and Iversen, L. L. (1974). Huntington's chorea. Post-mortem measurement of glutamic acid decarboxylase, choline acetyltransferase and dopamine in basal ganglia. Brain, 97, 457-472.

Bruyn, G. W. (1968). Huntington's chorea. Historical, clinical and laboratory synopsis. In Handbook of Clinical Neurology, 6, 298-378. Edited by P. J. Vinken and G. W. Bruyn. North-Holland: Amsterdam.

Cools, A. R. (1972). Athetoid and choreiform hyperkinesias produced by caudate application of dopamine in cats. Psychopharmacologia, 25, 229-237.

Curzon, G., Gumpert, J., and Sharpe, D. (1972). Amine metabolites in the cerebrospinal fluid in Huntington's chorea. Journal of Neurology, Neurosurgery, and Psychiatry, 35, 514-519.

Dom, R., Baro, F., and Brucher, J. M. (1973). A cytometric study of the putamen in different types of Huntington's chorea. In Advances in Neurology, 1, 369-385. Edited by A. Barbeau, T. N. Chase, and G. W. Paulsson. Raven Press: New York.

Emson, P. C., and Fonnum, F. (1973). Application of microchemical analysis to the characterization of neurones from the brain of Helix aspersa. In Psychopharmacology, Sexual Disorders and Drug Abuse, pp. 555-561. Edited by T. A. Ban, J. R. Boissier, G. J. Gessa, H. Heimann, L. Hollister, H. E. Lehmann, I. Munkvad, H. Steinberg,
F. Sulser, A. Sundwall, and O. Vinar. North-Holland: Amsterdam.

Fonnum, F. (1969). Radiochemical micro assays for the determination of choline acetyltransferase and acetylcholinesterase activities. Biochemical Journal, 115, 465-472.

Fonnum, F. (1973). Recent developments in biochemical investigations of cholinergic transmission. Brain Research, 62, 497-507.

Glover, V., and Green, D. P. L. (1972). A simple quick microassay for choline acetyltransferase. Journal of Neurochemistry, 19, 2465-2466.

Hebb, C. O., and Silver, A. (1956). Choline acetylase in the central nervous system of man and some other mammals. Journal of Physiology, 134, 718-728.

Hemminki, K., Hemminki, E., and Giacobini, E. (1973). Activity of enzymes related to neurotransmission in neuronal and glial fractions. International Journal of Neurosciences, 5, 87-90.

Ishii, T., and Friede, R. L. (1967). A comparative histochemical mapping of the distribution of acetylcholinesterase and nicotinamide adenine dinucleotide-diaphorase activities in the human brain. International Review of Neurobiology, 10, 231-275.

Johnson, S., and Domino, E. F. (1971). Cholinergic enzymatic activity of cerebrospinal fluid of patients with various neurologic diseases. Clinica Chimica Acta, 35, 421-428.

Klawans, H. L., Jr, and Rubovits, R. (1972). Central cholinergic-anticholinergic antagonism in Huntington's chorea. Neurology (Minneap.), 22, 107-116.

Lynch, G. S., Lucas, P. A., and Deadwyler, S. A. (1972). The demonstration of acetylcholinesterase containing neurones within the caudate nucleus of the rat. Brain Research, 45, 617-621.

McGeer, P. L., and McGeer, E. G. (1971). Cholinergic enzyme systems in Parkinson's disease. Archives of Neurology, 25, 265-268.

McGeer, P. L., McGeer, E. G., and Fibiger, H. C. (1973). Choline acetylase and glutamic acid decarboxylase in Huntington's chorea. A preliminary study. Neurology (Minneap.), 23, 912-917.

McGeer, P. L., McGeer, E. G., Fibiger, H. C., and Wickson, V. (1971). Neostriatal choline acetylase and cholinesterase following selective brain lesions. Brain Research, 35, 308-

Mattsson, B. (1974). Clinical Genetic and Pharmacological Studies in Huntington's Chorea. Thesis. Umeå University: Umeå.

314.

Rinne, U. K., Riekkinen, P., Sonninen, V., and Laaksonen, H. (1973). Brain acetylcholinesterase in Parkinson's disease. Acta Neurologica Scandinavica, 49, 215-226.

Rossier, J., Bauman, A., and Benda, P. (1973). Antibodies to rat brain choline acetyltransferase: species and organ specificity. FEBS Letters, 36, 43-48.

Silver, A. (1967). Cholinesterases of the central nervous system with special reference to the cerebellum. International Review of Neurobiology, 10, 57-109.

Wise, C. D., Baden, M. M., and Stein, L. (1974). Postmortem measurement of enzymes in human brain: evidence of a central noradrenergic deficit in schizophrenia. Journal of Psychiatric Research, 11, 185-198. 